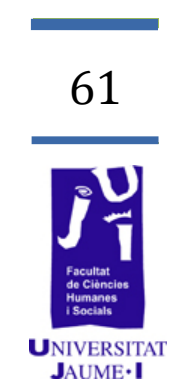

\title{
Arte e iconografía maya: la representación de los adornos corporales en las mujeres de la élite
}


La antigua nobleza maya dejó patente la huella de su paso por las tierras mesoamericanas en forma de valiosas obras de arte. El carácter simbólico de dichas expresiones artísticas resulta ahora transcendental para conocer mejor a una cultura de la que, por diversas circunstancias, apenas se conservan documentos escritos.

Por este motivo, planteamos un estudio iconográfico con la intención de aproximarnos al conocimiento de un aspecto muy concreto de esta civilización, el colectivo femenino, que, hasta estas últimas décadas, siempre ocupó un segundo plano en la historiografía mayista, y se vale de las posibilidades y perspectivas que nos ofrece la historia del arte.

De este modo, el enfoque que planteamos utiliza los adornos corporales -elementos sumamente significativos y prolíficos en las representaciones- como hilo conductor, medio a través del cual acercarnos a la realidad de sus portadoras y la presencia de estas en el arte $y$, en consecuencia, en la cultura maya.

Aquellas antiguas damas no han dejado de representarse igual o más engalanadas que sus compañeros varones, sus nombres y hazañas también ocupan un lugar en las representaciones y todavía existen numerosos aspectos sobre ellas que, si se investigan correctamente, tienen mucho que enseñarnos sobre estas poderosas mujeres.

Palabras clave: iconografía, maya, mujeres, adornos corporales, género, alto rango, historia, arte.

\section{Introducción}

El clima extremo, la densa vegetación selvática, la fauna salvaje, las acciones del ser humano y, en conjunto, los estragos causados por el paso del tiempo fueron sepultando los vestigios de la que fuera una de las civilizaciones más desarrolladas y duraderas de la América prehispánica: la cultura maya. No obstante, son muchos los investigadores que, desde diferentes disciplinas, han ido contribuyendo a la reconstrucción de la historia de esta cultura. La labor de antropólogos, arqueólogos, epigrafistas, historiadores, arquitectos y restauradores, por citar algunos, ha sido fundamental para dar a conocer el pasado de los pueblos mayas y recuperar una enorme cantidad de vestigios arqueológicos y arquitectónicos diseminados en un área de más de $324.000 \mathrm{~km}^{2}$. A este respecto cabe destacar que muchos de estos hallazgos son de carácter artístico; es más, se han conservado y recuperado muchas más imágenes mayas en diferentes soportes plásticos (vasijas cerámicas, muros, códices, relieves, etc.) que documentos escritos. Por lo tanto, el papel que juega la historia del arte en el estudio de esta antigua cultura precolombina es sumamente importante. 
En este sentido, el método iconográfico-iconológico nos permite profundizar en el significado de las obras de arte maya y entender en qué medida reflejan el contexto en el que se crearon, al mismo tiempo que nos desvelan qué función tuvieron y cuál fue su intencionalidad.

Asimismo, este trabajo se inserta en la línea de los estudios de género puesto que, a pesar de que esta rama ha ido adquiriendo más protagonismo en el ámbito académico en estos últimos años, continúan existiendo muchos vacíos de conocimiento debido al segundo plano al que se ha relegado a este tipo de estudios en el pasado.

En síntesis, mediante este análisis pretendemos sumarnos a esa corriente de investigadores que abogan por hacer aportaciones en un campo de estudio todavía incipiente, como es el de los estudios de género mayas. Para ello se emplean las ventajas que nos ofrecen las herramientas y los enfoques propios de nuestra disciplina, la historia del arte. Además, partimos del estudio de los adornos corporales, puesto que somos conscientes de la importancia que, desde el punto de vista cultural, tienen los detalles más pequeños en las imágenes, la riqueza epistemológica de su iconografía. Así pues, consideramos que elementos tan apreciados en aquellas culturas, como eran las joyas, los tocados o los cosméticos, son idóneos para indagar acerca de los individuos que los portaban, concretamente las mujeres, para aproximarnos de una manera original al significado de su presencia en las representaciones artísticas y, en consecuencia, a la trascendencia de cada obra y de sus protagonistas femeninas en el seno de esta antigua sociedad precolombina.

\section{Objetivos}

El objetivo principal que persigue este trabajo es desarrollar un estudio en torno a la figura de la mujer de alto rango en el contexto de la civilización maya a través de los atributos que porta en sus representaciones.

Dicho objetivo se materializará finalmente como consecuencia del cumplimiento de una serie de objetivos específicos expuestos a continuación.

- Definición de las distintas categorías establecidas para el análisis de los personajes femeninos de la élite desde una perspectiva de género.

- Análisis y clasificación de los diferentes adornos corporales utilizados por las mujeres en la antigüedad maya.

Análisis e interpretación iconográfica de las obras de arte seleccionadas. 


\section{Material y método}

Al tratarse de un estudio que tiene por objeto las representaciones artísticas de los antiguos mayas, trabajamos principalmente con fuentes visuales, primarias, directas y necesariamente de segunda mano. Concretamente, reproducciones y fotografías de las obras de arte accesibles en libros sobre la materia o catálogos de museos que conservan obras de arte precolombinas. Asimismo, nos valemos del material gráfico disponible en bases de datos especializadas, fundamentalmente, la base de datos fotográfica de Justin Kerr, ${ }^{1}$ donde podemos visualizar una enorme cantidad de representaciones mayas al completo, que fueron plasmadas sobre vasijas, platos y vasos cerámicos. Muchas de estas piezas no serían accesibles de otro modo, ya que pertenecen a coleccionistas privados.

Del mismo modo, consultamos fuentes de carácter literario. Desde las versiones actuales, traducidas y comentadas de relatos mitológicos como el Popol $\mathrm{Vuh}^{2}{ }^{2}$ pasando por fuentes etnohistóricas como las transcripciones y ediciones actuales del manuscrito de Diego de Landa ${ }^{3}$ hasta las reproducciones de dos de los tres códices mayas, ${ }^{4}$ expuestos uno de ellos en el Museo de América de Madrid y el otro en la biblioteca estatal de Dresde. Este tipo de fuentes, junto con el estudio de la bibliografía complementaria (estudios críticos sobre las cuestiones que nos atañen: la cultura maya, la antigua mujer maya o trabajos precisos sobre iconografía y adornos corporales), que compone el corpus principal de materiales empleados, nos permiten conocer, contrastar y sentar las bases teóricas sobre las cuales construir nuestro discurso posterior, fruto del análisis de las imágenes.

Así pues, el manejo de este tipo de materiales nos lleva a plantear dos métodos de estudio.

Comenzamos con la investigación siguiendo el método historiográfico. Con el fin de alcanzar satisfactoriamente las metas propuestas, se efectúa un acercamiento inicial en el que a través de búsquedas, ayudados por las ventajas que ofrecen las nuevas tecnologías, recuperamos y guardamos de manera selectiva información sobre el tema que vamos a trabajar. A la busca y selección de las fuentes visuales mayas se suma la de fuentes textuales y de bibliografía específica, citadas anteriormente. Con la intención de hallar todo el material, sin obviar la consulta y lectura de estudios imprescindibles y tratando de visualizar y recopilar el mayor número de imágenes posible, dedicamos cerca de dos meses y medio a esta fase, crucial en todo tipo de investigaciones.

Finalmente, recurrimos al método iconográfico-iconológico, mencionado en el apartado introductorio, estructurado en el siglo xx por

1. @JustinKerr <www.mayavase.com>

2. Rivera (ed.), 2008.

3. Landa, 2002.

4. Manuscritos mayas que, por sus características y su originalidad, componen una de las fuentes más fiables sobre la antigua civilización precolombina. Actualmente, solo se conservan tres: uno de ellos en Dresde, otro en Madrid y otro en París. 
el historiador del arte Erwin Panofsky, desarrollado en su obra Studies in Iconology: Humanistic Themes in the Art of the Renaissance, ${ }^{5} \mathrm{y}$ enriquecido con las recientes investigaciones llevadas a cabo por el profesor Rafael García Mahíques, ${ }^{6}$ con el fin de profundizar en el estudio de las representaciones femeninas de élite en el arte maya, escogidas en la fase heurística anterior. Dicha selección se efectúa atendiendo a las necesidades de nuestro estudio, es decir, qué imágenes contienen las muestras más representativas de todo aquello que estudiamos y pretendemos demostrar. Retomando la cuestión metodológica, este procedimiento parte de un acercamiento progresivo a la obra estructurado en tres fases: localización, análisis formal y aproximación al significado (análisis iconográfico-iconológico), procurando abarcarla en todas sus vertientes. En este sentido cada aportación es fundamental, pues de la correcta ejecución de la primera parte dependerá la veracidad de la siguiente, y así sucesivamente. De este modo podemos llegar a entender la función de la obra como un factor de creación cultural que influye, en la misma medida en la que se impregna, en el entorno que la rodea. El sentido de esta metodología queda así resumido en palabras de Panofsky (1987: 187):

En una obra de arte, la forma no puede separarse del contenido; la distribución del color y las líneas, la luz y la sombra, los volúmenes y los planos, por delicados que sean como espectáculo visual, deben entenderse también como algo que comporta un significado que sobrepasa lo visual.

Esta última parte de la investigación requiere, además del manejo de las imágenes, trabajar con la información obtenida mediante el método anterior, con la finalidad de extraer conclusiones propias y aportar nuevas perspectivas a este campo de estudio. Completar esta labor nos lleva un mes y medio de trabajo.

\section{Resultados}

De acuerdo con los objetivos planteados inicialmente, la primera parte de este trabajo se centra en el estudio de la mujer maya de alto rango en el seno de su sociedad, qué funciones cumplía y qué características la definían. De este modo, las clasificamos en tres grupos:

\section{REINAS}

- Por lo general, fueron esposas de gobernantes o madres regentes.

- Aparecen lujosamente ornamentadas en las representaciones.

- Se les reconoció la función de legitimar el linaje real generación tras generación. 
- Protagonizaron actos importantes tanto en el plano ritual como en el político, realizando autosacrificios de sangre $u$ otorgando las insignias del poder a su descendiente, por ejemplo.

\section{MUJERES DE LA CORTE}

- Fueron personajes femeninos de la nobleza, normalmente mujeres de hombres importantes o familiares cercanas de los gobernantes.

- Se las representa en escenas palaciegas.

- Asumían tareas trascendentales tales como la hechicería, el arte de tejer, el cuidado de las parturientas o la danza ritual. También hubo quienes tuvieron el honor de ser escribas y pintoras.

- Lucían ricos ropajes y se engalanaban con joyas, pero en menor medida que las reinas.

\section{MUJERES EN EL ÁMBITO SOBRENATURAL}

- Se trata de las deidades femeninas del panteón maya.

- Desempeñaron funciones tan importantes como las de los dioses. De hecho, en la mayoría de los casos, ambos sexos necesitaban complementar sus funciones para llevar a cabo alguna acción.

- En ocasiones se las representa ejerciendo labores terrenales, ya que se constituían como modelos celestiales de las mujeres de la tierra.

- Son fáciles de reconocer puesto que la tradición las vincula con unas determinadas cualidades y funciones representadas por atributos concretos con los que siempre aparecen.

En segundo lugar, agrupamos y analizamos los adornos corporales empleados frecuentemente por el género femenino en el área maya. Obtenemos así una clasificación general, nuevamente en tres grupos, que nos permite ordenar y conocer este tipo de prácticas y piezas:

\section{MODIFICACIÓN CORPORAL}

Aquellas prácticas que suponen una transformación de carácter permanente y que inciden directamente en la fisionomía del ser humano: 
Tabla 1. Modificaciones corporales más características: fragmento del roll out de la vasija de cerámica policromada K6888 que muestra la deformación craneal de una noble / Fragmento de la figurillla K3803 que muestra una dentadura limada en forma de T según el diseño IK

\begin{tabular}{|c|c|}
\hline Deformación craneana & Decoración dental \\
\hline $\begin{array}{c}\text { Consiste en moldear el cráneo hasta } \\
\text { conseguir la forma deseada. Esta } \\
\text { práctica se llevaba a cabo desde el } \\
\text { nacimiento y tenía como finalidad } \\
\text { asemejarse al Dios del Maíz. }\end{array}$ & $\begin{array}{c}\text { Se trata de incisiones, limados, } \\
\text { perforaciones, pintadas e } \\
\text { incrustaciones de piedras preciosas, o } \\
\text { varias de estas técnicas combinadas } \\
\text { sobre la dentadura. }\end{array}$ \\
\hline
\end{tabular}

\section{ORNAMENTOS}

Complementos materiales adheridos al cuerpo que, aunque a veces también suponían una modificación, por ejemplo al perforar, ésta no conformaba una decoración por sí misma como ocurría con las anteriores, si no que se efectuaba por la necesidad de colocar la pieza. En este aspecto distinguimos entre tocados y adornos en el cabello, y joyas:

Tabla 2. Tocados y adornos en el cabello clasificados según nivel de complejidad: fragmento del roll out de la vasija de cerámica policromada K2794 (coleta) / Fragmento del roll out de la vasija de cerámica policromada K0764 (pañuelo) / Fragmento del roll out de la vasija de cerámica policromada K1202 (tocado sencillo) / Fragmento del roll out de la vasija de cerámica policromada K1377 (tocado complejo)

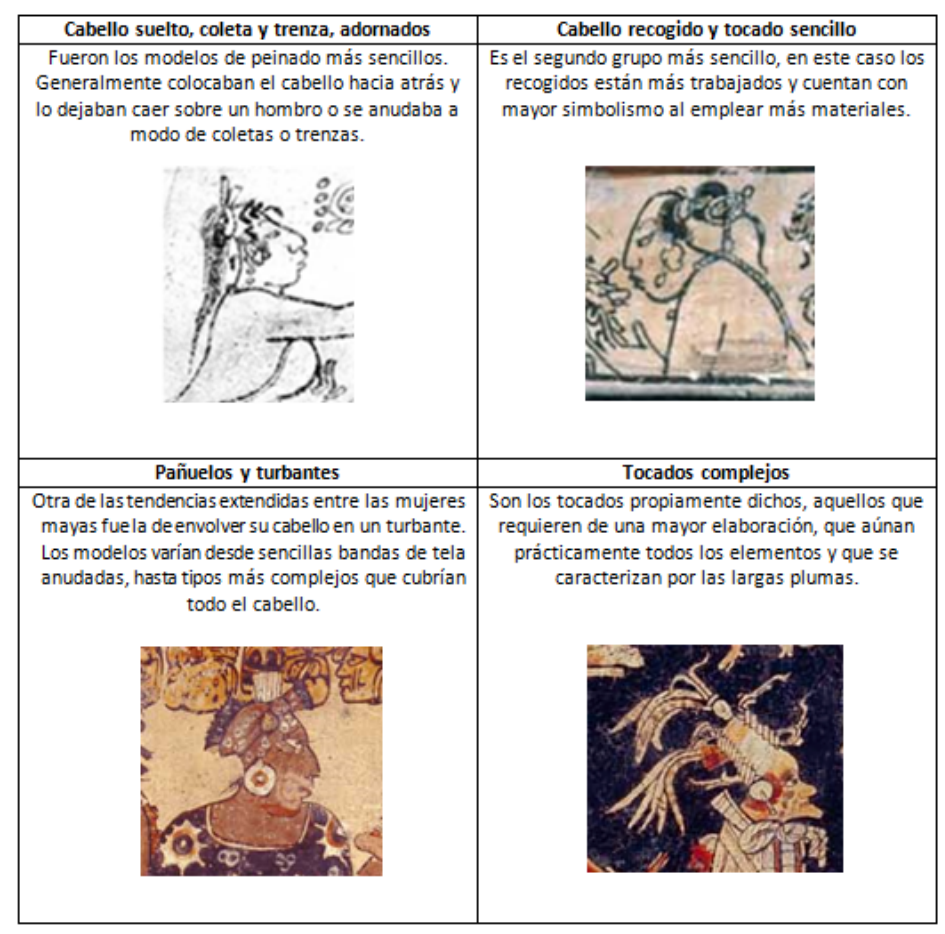


Tabla 3. Joyas principales

\begin{tabular}{|c|c|c|c|}
\hline Orejeras & Narigueras & Collares & Pectorales \\
\hline $\begin{array}{l}\text { Tipo de ornamento que } \\
\text { decora de forma muy } \\
\text { vistosa los lóbulos de } \\
\text { las orejas. Se trata de } \\
\text { uno de los distintivos } \\
\text { principales de las clases } \\
\text { altas y su forma más } \\
\text { común fue la que } \\
\text { imitaba una flor. }\end{array}$ & $\begin{array}{l}\text { Fue una pieza exclusiva } \\
\text { de las divinidades y las } \\
\text { clases altas. Existieron } \\
\text { diversos tipos que se } \\
\text { colocaban en la nariz, o } \\
\text { bien a modo de } \\
\text { decoración, o con la } \\
\text { intención de asemejarse } \\
\text { a sus dioses. }\end{array}$ & $\begin{array}{l}\text { Fue un atributo de poder } \\
\text { fabricado generalmente } \\
\text { en jade, jadeíta y } \\
\text { concha. Las formas de } \\
\text { sus piezas variaban pero } \\
\text { el diseño más común fue } \\
\text { el fabricado mediante } \\
\text { cuentas tubulares o } \\
\text { esféricas. }\end{array}$ & $\begin{array}{l}\text { Similares a los collares, } \\
\text { merecieron una } \\
\text { atención especial por la } \\
\text { cantidad de atributos } \\
\text { simbólicos de los que } \\
\text { se componían. Su gran } \\
\text { tamaño permitía, a su } \\
\text { vez, diseños más } \\
\text { variados. }\end{array}$ \\
\hline Pulseras & Brazaletes & Muñequeras & Tobilleras \\
\hline $\begin{array}{l}\text { Elementos finos que se } \\
\text { colocaba en las } \\
\text { muñecas y que se } \\
\text { fabricaba también con } \\
\text { materiales preciados, } \\
\text { contribuyendo a } \\
\text { construir la imagen de } \\
\text { poder de las mujeres } \\
\text { de élite. }\end{array}$ & $\begin{array}{l}\text { Fueron ornamentos } \\
\text { muy similares a las } \\
\text { pulseras que } \\
\text { únicamente se } \\
\text { diferenciaban de éstas } \\
\text { por su colocación. En } \\
\text { este caso, se ceñían en } \\
\text { el extremo superior del } \\
\text { brazo }\end{array}$ & $\begin{array}{l}\text { El uso de estas piezas } \\
\text { estuvo muy extendido } \\
\text { entre la corte. Los } \\
\text { personajes que } \\
\text { aparecen ricamente } \\
\text { ataviados siempre } \\
\text { cuentan con estas } \\
\text { piezas cubriéndoles un } \\
\text { tercio del antebrazo. }\end{array}$ & $\begin{array}{c}\text { Al igual que en los } \\
\text { brazos lucían pulseras o } \\
\text { muñequeras, los } \\
\text { tobillos se decoraron } \\
\text { con estos ornamentos } \\
\text { de uso cotidiano. Los } \\
\text { materiales principales } \\
\text { para su fabricación } \\
\text { fueron el jade y la tela. }\end{array}$ \\
\hline
\end{tabular}

PINTURA CORPORAL

Este fue uno de los primeros recursos empleados por el ser humano para cambiar su apariencia natural. Cubrían su piel parcial o totalmente con pigmentos de color, creando diseños y patrones con una finalidad estética y simbólica.

Con el tiempo, el deseo de mantener algunos de estos diseños de manera permanente sobre la piel les llevó a practicar también los tatuajes y las escarificaciones. Para realizar los primeros, se seguía la técnica de punción prácticamente igual que la que conocemos hoy en día. Y en las escarificaciones, heridas intencionadas con las formas deseadas, con la intención de que el dibujo quedara marcado, se insertaban tierra de colores en la piel para que las cicatrices quedaran abultadas y coloridas.

Finalmente, escogemos seis obras de arte representativas sobre las cuales aplicamos el método de análisis iconográfico-iconológico. Esta cuidada selección nos permite acercarnos a cada tipo de mujer: diosa, reina y cortesana. Asimismo, optamos también por estudiarlas representadas en diferentes soportes plásticos: un códice iluminado en el que aparece una diosa, una escultura donde nos aproximamos al ritual sagrado de una conocida reina, una pintura mural donde se aprecia el contraste social de una mujer de la corte frente a una plebeya y tres ejemplos diferentes de mujeres de alto rango presentes sobre uno de los soportes más prolíficos en imágenes mayas, las vasijas de cerámica policromada: 


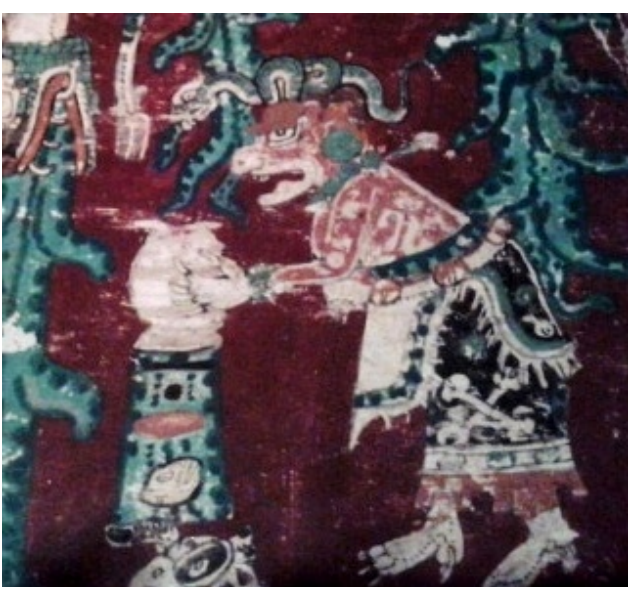

Figura 3. Fragmento de la pàgina 39 del códice de Dresde. Representación de la diosa Ixchel en su versión anciana

Figura 4. Fragmento del dintel 24 de Yaxchilán. Representación de la señora Xoc realizando un autosacrificio de sangre

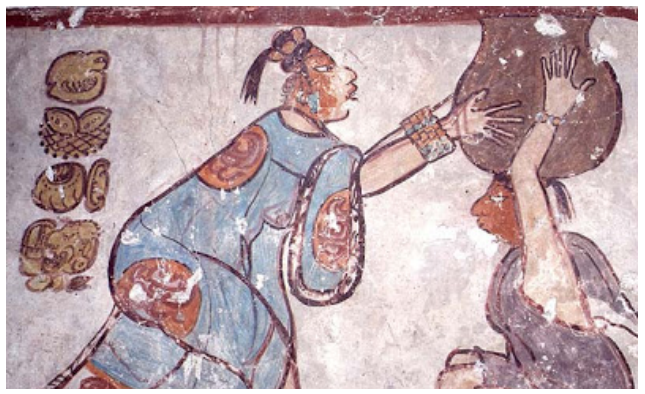

Figura 5. Fragmento de la escena de la cara sudeste de la base de la estructura de los murales de Calakmul. Representación de la noble del huipil azul

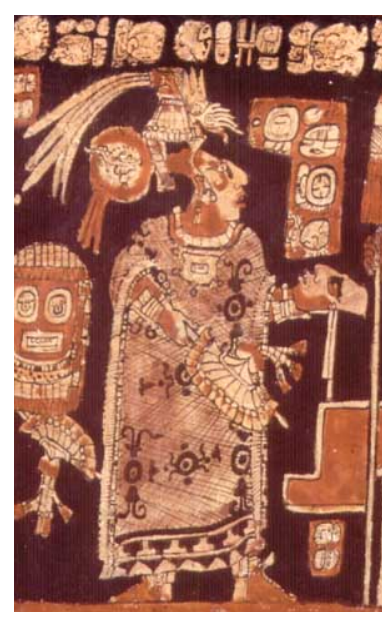

Figura 7. Fragmento del roll out de la vasija de cerámica policromada K2695. Representación de la esposa del gobernante ricamente ataviada
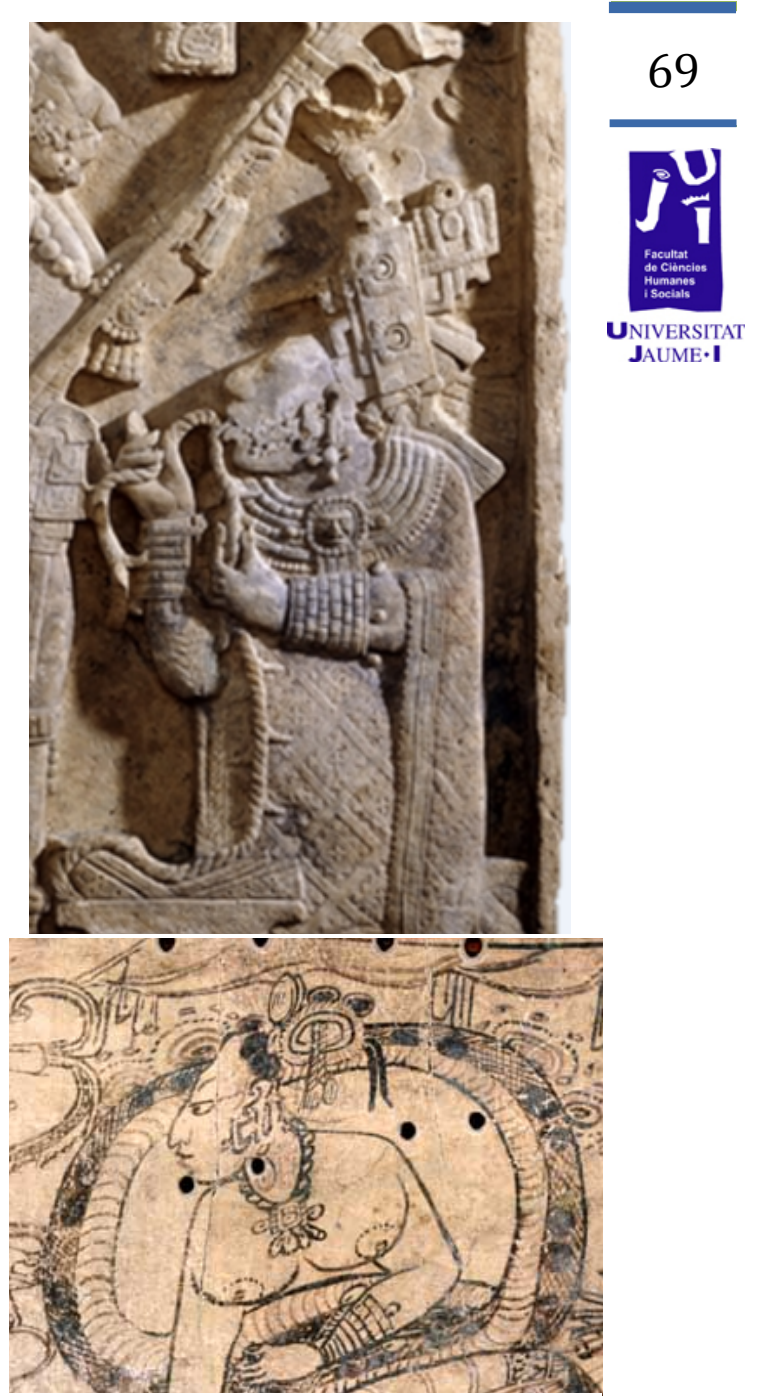

Figura 6. Fragmento del roll out de la vasija de cerámica K1198.

Representación de la señora Dragón

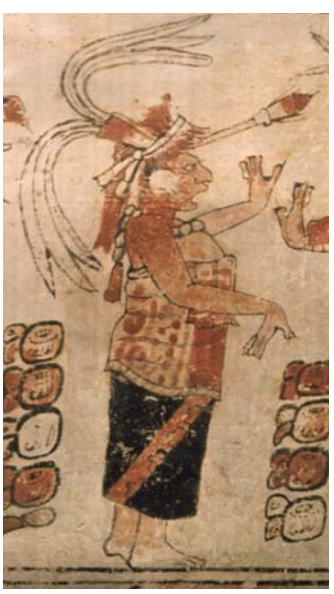

Figura 8. Fragmento del roll out de la vasija de cerámica policromada K0554. Retrato de una noble danzando 
Así pues, el resultado más destacado de este análisis es que verdaderamente los adornos corporales cumplen una función básica: identificar a su portador, en este caso portadora, en las representaciones. No solo nos permiten situarlas en una escala social (distinción entre nobles y plebeyas) y diferenciarlas entre ellas (reinas, diosas y nobles) dentro de un mismo rango, sino que además ofrecen información de carácter personal como el oficio que tenían en la corte o la función que cumplían como diosas, de carácter cultural -puesto que algunas presentan elementos propios de la cultura teotihuacana, testimonio de los contactos que hubo entre ambas civilizaciones- $y$, especialmente, de carácter religioso -pues desde los materiales con los que se fabricaban, pasando por la parte del cuerpo y quién las lucía, hasta el acto mismo de ponerse estos adornos, tuvieron connotaciones sagradas y rituales.

\section{Discusión y conclusiones}

La aproximación a los adornos corporales en las representaciones de las mujeres de alto rango en el arte maya nos ha ofrecido la posibilidad de profundizar de manera enriquecedora en uno de los aspectos culturales más interesantes de una civilización.

Las conclusiones que se han ido desprendiendo a medida que avanzaba el trabajo han sido las que han permitido posteriormente realizar un análisis iconográfico adecuado ya que nos han proporcionado las bases teóricas sobre las cuales fundamentar nuestras interpretaciones.

En primer lugar, del estudio de la mujer maya en el seno de su civilización se deduce una participación social y cultural destacada. Son numerosos, aunque recientes en el tiempo, los estudios que, independientemente de su inclinación acerca de cómo fue tratada la mujer con respecto al hombre en el pasado, documentan la cantidad de labores que desempeñaban para sus pueblos en todos los ámbitos: social, político y religioso. Y esto es especialmente palpable entre las mujeres de alto estatus, quienes desempeñaban trabajos indispensables.

Gracias a la lectura y el análisis exhaustivo de la bibliografía que se ocupa del estudio de la mujer maya hemos sido capaces de discernir cuáles eran los papeles que desempeñaban y qué prácticas se relacionaban con un tipo de mujer $u$ otra, consiguiendo así establecer las características propias de cada categoría, distinguiendo y definiendo a reinas, cortesanas y diosas. El hecho de haber acotado este estudio únicamente a la figura de la mujer nos ha proporcionado, además, la posibilidad de extraer la máxima información sobre este sector de la población maya, lo cual nos permite, a su vez, llegar a conclusiones más específicas en el análisis iconográfico posterior, pues al centrar nuestro objeto de estudio atendemos a detalles -a veces descuidados- que nos aportan buena información y nos permiten ofrecer otro punto de vista. 
En segundo lugar, la investigación de los adornos corporales nos ha proporcionado las herramientas necesarias para poder reconocerlos e interpretarlos en las obras de arte. Asimismo, hemos podido efectuar una selección de los adornos concretos que tuvieron más cabida en el ámbito femenino de la corte (tanto terrenal como sobrenatural) y hemos proporcionado un análisis y una clasificación propios, orientados al ámbito artístico. Por un lado, destaca la importancia de la selección de los materiales, entre los cuales el jade fue el más preciado, pues lo reservaban para las élites $y$, cuando lo empleaban, lo hacían en abundancia y lo colocaban en lugares visibles para que el mensaje llegara correctamente. Sin embargo, no solo valoraron el jade, sino también las plumas y la variedad de colores de estas, el nácar que obtenían de la concha de caracoles marinos con dificultad, etc. Algunos considerados bienes de lujo por la dificultad de su obtención y otros por el simbolismo de sus colores. En síntesis, el material le daba calidad y valor añadido a los adornos que por sí mismos ya se fabricaban con una misión: comunicar.

En última instancia, es en el análisis iconográfico efectuado tras el estudio previo de la cultura, las mujeres y sus adornos corporales, donde se ponen en práctica las reflexiones extraídas. En este sentido, las imágenes analizadas nos han permitido, entre otras cosas, aportar algunas conclusiones que consideramos de interés a escala general. Una muestra de ello, además de la posibilidad que nos ofrecen los adornos corporales de obtener información sobre sus portadoras tal y como mencionábamos al final del apartado anterior, es que hemos podido observar que, de las seis figuras femeninas estudiadas, tres adquieren más protagonismo en las escenas que los varones que las acompañan (Ixchel, la señora Xoc y la noble del huipil azul), dos de ellas se muestran al mismo nivel que ellos, tanto en acciones como en ornamentos (la reina en la vasija K2695 y la artista-escriba en la vasija K0554) y solo una de ellas se encuentra en una posición más débil con respecto al género masculino (la señora Dragón), pero el papel que desempeña es igualmente importante en el capítulo que se representa en esta escena de la mitología maya. Por lo tanto, queda demostrada la participación activa y reconocida de muchas mujeres mayas del pasado en su sociedad, cuyos nombres y acciones quedan también grabados en la historia de sus muros, estelas y pinturas, engalanadas igual que los hombres.

Asimismo, este análisis nos permite incidir, además de en la cuestión de género, en la cuestión religiosa. Y es que para los mayas sus creencias actuaron como pilares de su existencia. Por ello, si prestamos atención más allá del valor y la función de estos objetos y de estas prácticas por motivos políticos y sociales, observamos la presencia continua de símbolos, de materiales simbólicos, de representaciones directas de divinidades y la intención de portar muchos de estos adornos y ejecutar muchas de estas modificaciones con tal de asemejarse a sus dioses.

En síntesis, estas reflexiones prueban que un estudio riguroso sobre las representaciones no solo puede aportar y completar información, sino que puede ayudar a resolver algunos interrogantes acerca de esta antigua 
civilización que la arqueología o la antropología no alcanzan a responder. En este caso en concreto, nos hemos centrado en los adornos corporales para aproximarnos a las representaciones de la mujer de la élite, pero en un futuro se podría enriquecer incluyendo también el estudio de la indumentaria.

A grandes rasgos, este trabajo ofrece una panorámica sobre los adornos corporales, y concretamente femeninos, que la historiografía, aunque sintética, no ha tratado específicamente. De este modo, no solo se ha pretendido plantear un estudio con vistas a una futura investigación de mayor envergadura, sino que además se ha intentado reivindicar, por una parte, la imprescindible labor de la historia del arte en el análisis de las abundantes imágenes que los mayas nos han legado y, por otra, la función que las antiguas obras de arte maya desempeñaron en su tiempo y que todavía tienen mucho que aportar si se estudian detenidamente en la actualidad.

\section{Bibliografía}

Ardren, T. (2002): Ancient Maya Women, Altamira Press, Walnut Creek.

BaUtista MARTínez, J. (2002): "Alteraciones culturales en el cuerpo del hombre prehispánico», Estudios Mesoamericanos, Universidad Nacional Autónoma de México.

Fuente, B y A. Arellano (2001): El hombre maya en la plástica antigua, Universidad Nacional Autónoma de México, México.

García MahíQues, R. (2009): Iconografía e iconología. Volumen 2. Cuestiones de método, Ediciones Encuentro, Madrid.

JoYCE, R. (2001): Gender and Power in Prehispanic Mesoamerica, University of Texas, Austin.

LANDA, D. (2002): Relación de las cosas de Yucatán, Dastin, Madrid.

Martin, S. y N. Grube (2002): Crónica de los reyes y reinas mayas. La primera historia de las dinastías mayas, Editorial Crítica, Barcelona.

PANOFSKY, E. (1939): Studies in Iconology: Humanistic Themes in the Art of the Renaissance, Oxford University Press, Nueva York.

- (1987): El significado de las artes visuales, Alianza Forma, Madrid.

Rivera Dorado, M. (ed.) (2008): Popol Vuh, Trotta, Madrid.

ROdRIGUEZ-SHAdOW, M. J. y S. KELLOG (ed.) (2013): Género y arqueología en Mesoamérica. Homenaje a Rosemary A. Joyce, Centro de Estudios de Antropología de la Mujer, México.

Rodríguez-Shadow, M. J. y M. López HeRnÁndez (ed.) (2011): Las mujeres mayas en la antigüedad, Centro de Estudios de Antropología de la Mujer, México. 
Stone, A. y M. Zender (2011): Reading Maya Art. A Hieroglyphic Guide to Ancient Maya Painting and Sculpture, Thames \& Hudson, Londres.

Vela RAmírez, E. (ed.) (2010): «Decoración corporal prehispánica», Arqueología Mexicana.

- (ed.) (2015): «La joyería en el México antiguo», Arqueología Mexicana.

VIDAL LORENZO, C. (2005): "La mujer maya y su papel político y religioso», Alfaro Giner, C. (ed.): Protai Gynaikes: Mujeres próximas al poder en la antigüedad, Sema V-VI, Valencia.

* Las imágenes han sido extraídas de la base de datos @JustinKerr www.mayavase.com. 